\title{
WYKORZYSTANIE TURYSTYCZNE DZIEDZICTWA KULTUROWEGO
} KASZUBÓW

\section{L'EXPLOITATION TOURISTIQUE DE L'HÉRITAGE CULTUREL} DE LA KACHOUBIE

\section{TOURIST USE OF THE CULTURAL HERITAGE OF THE KASHUBY}

\begin{abstract}
Dziedzictwo kulturowe Kaszubów jest, obok walorów środowiska przyrodniczego, jednym z podstawowych elementów stanowiących o atrakcyjności turystycznej Pojezierza Kaszubskiego. Artykuł zawiera jego krótką charakterystykę oraz prezentuje wyniki badań ruchu turystycznego przeprowadzonych w dwóch muzeach etnograficznych regionu.
\end{abstract}

\section{WSTĘP}

Przedmiotem pracy jest dziedzictwo kulturowe Kaszubów na obszarze Kaszub Środkowych i Południowych ${ }^{1}$. Pojęcie dziedzictwa kulturowego obejmuje wszelkie przejawy tradycyjnej kultury ludowej, na którą składają się elementy kultury materialnej oraz wytwory kultury duchowej w postaci sztuki, folkloru i obrzędowości. Podstawowym celem pracy jest ocena wykorzystania dziedzictwa kulturowego Kaszubów przez ruch turystyczny. Cel ten realizowany był na podstawie charakterystyki ruchu turystycznego - jego wielkości, sezonowości,

${ }^{1}$ Artykul opracowano na podstawie pracy magisterskiej pt. Dziedzictwo kulturowe Kaszubów $i$ jego wykorzystanie $w$ turystyce, wykonanej przez autorkę na seminarium z geografii turyzmu w Katedrze Geografii Miast i Turyzmu UŁ w 1995 r., pod kierunkiem prof. dr. hab. Stanisława Liszewskiego. Promotor pracy - dr E. Dziegieć. 
form, struktury społeczno-demograficznej oraz pochodzenia terytorialnego uczestników ruchu.

Przy ustalaniu zasięgu przestrzennego badań wzięto pod uwagę granicę występowania języka kaszubskiego, granicę subregionów etnograficznych Kaszub Środkowych i Południowych oraz granicę administracyjną woj. gdańskiego. W wyniku tego uwzględniono obszar obejmujący dziewięć gmin położonych w południowo-zachodniej części woj. gdańskiego: Chmielno, Dziemiany, Karsin, Kartuzy, Kościerzyna, Lipusz, Sierakowice, Stężyca, Sulęczyno.

Praca opiera się na własnych badaniach terenowych, na które złożyły się inwentaryzacja elementów dziedzictwa kulturowego, obserwacje i wywiady przeprowadzone $w$ terenie oraz badania ruchu turystycznego $w$ muzeach etnograficznych. Materiałem źródłowym do badań ruchu turystycznego były sprawozdania z działalności muzeów oraz ankiety zebrane wśród turystów zwiedzających Muzeum Kaszubskie w Kartuzach i Kaszubski Park Etnograficzny we Wdzydzach Kiszewskich, w lipcu 1994 r. Lącznie w tych dwóch obiektach przeprowadzono 357 ankiet, w tym 314 wśród turystów indywidualnych i 43 wśród kierowników grup. Badania ankietowe pozwoliły na identyfikację uczestników ruchu turystycznego ze względu na ich cechy społeczno-demograficzne, miejsce pochodzenia i formę uprawianej turystyki. Były one ponadto podstawą do analizy motywów przybycia do muzeów oraz opinii na temat walorów ziemi kaszubskiej.

\section{CHARAKTERYSTYKA OBSZARU BADAŃ}

Pod względem fizycznogeograficznym obszar badań należy do pasa Pojezierzy Wschodniopomorskich i zajmuje południową i środkową część Pojezierza Kaszubskiego oraz północno-wschodnią Równiny Charzykowskiej (K o n d r a c k i 1988). Walory przyrodnicze regionu zadecydowały o tym, że jest on często nazywany Szwajcarią Kaszubską. Na jej krajobraz składa się urozmaicona rzeźba terenu ( $\mathrm{z}$ najwyższą kulminacją pojezierzy - Wieżyca), głęboko wcięte doliny rzek, bogactwo jezior, duże powierzchnie leśne.

Obszar położony jest na zapleczu aglomeracji Trójmiasta (rys. 1). Przez jego teren nie przebiega żadna $\mathrm{z}$ drós ani linii kolejowych o znaczeniu międzynarodowym czy krajowym, jednak gęsta sieć komunikacyjna niższego rzędu umożliwia w miarę swobodne poruszanie się po regionie. Przez najbardziej atrakcyjne krajobrazowo zakątki pojezierza prowadzą cztery znakowane szlaki turystyki pieszej, a liczne rzeki i połączone ze sobą jeziora stanowią naturalne szlaki komunikacji wodnej. Szwajcaria Kaszubska posiada dobrze rozwiniętą infrastrukturę turystyczną. Skupia ona ponad $20 \%$ obiektów i miejsc noclegowych całego woj. gdańskiego. Elementy środowiska naturalnego oraz zagospodarowanie ob- 


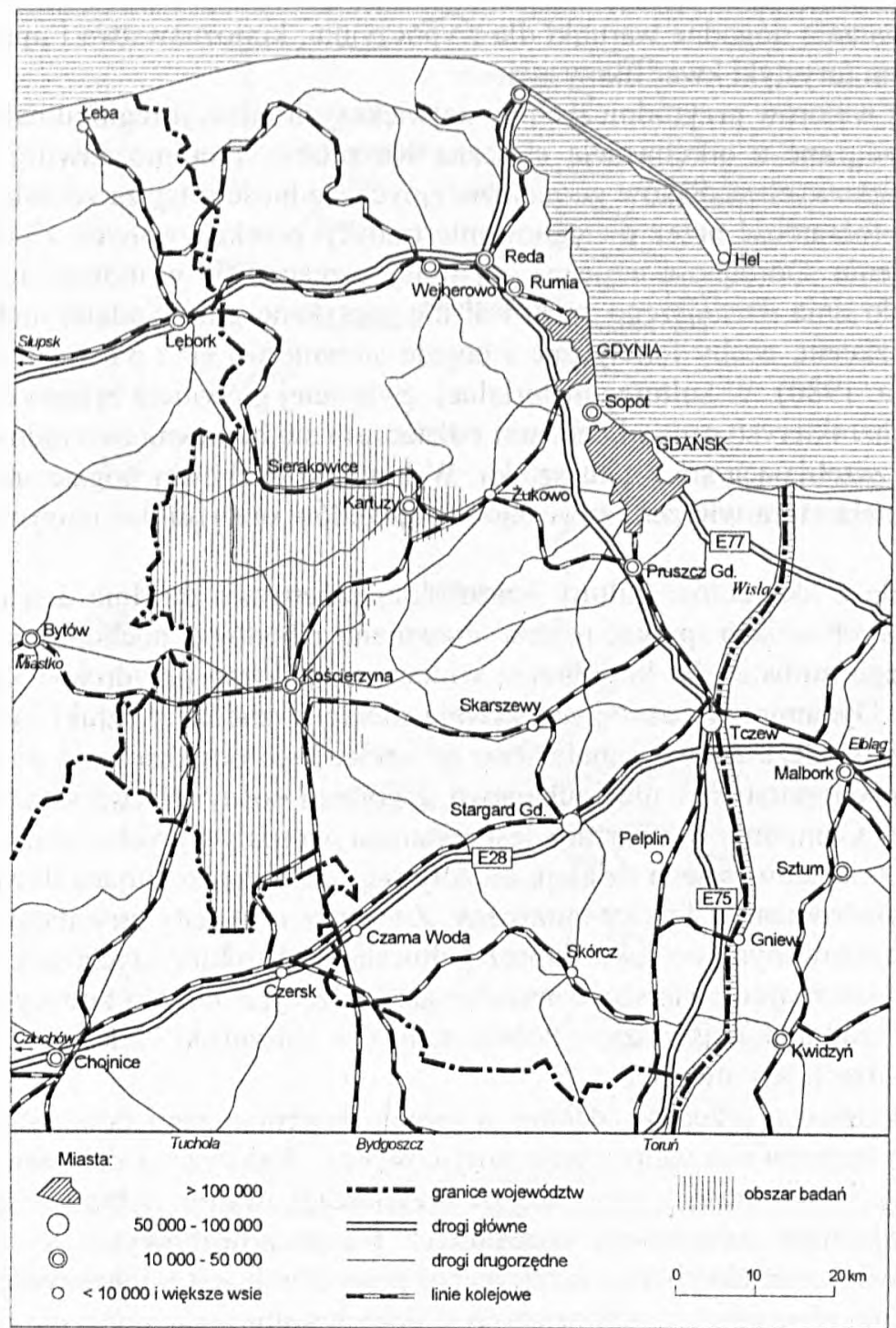

Rys. 1. Położenie administracyjno-komunikacyjne obszaru badań

1 - granice województw, 2 - drogi glówne, 3 - drogi drugorzędne, 4 - linie kolejowe, 5 - granice obszaru badań, 6 - miasta powyżej 100000 mieszkańców, 7 - miasta liczące 50 000-100 000 mieszkańców, 8-10 000-50 000 mieszkańców, 9-miasta liczące poniżej 10000 mieszkańców i większe wsie (ź r ó d ł o: opracowanie własne)

Dessin 1. La situation administrative et de communication du terrain examiné 1 - limites des voïvodies, 2 - routes importantes, 3 - autres routes, 4 - lignes ferroviaires, 5 - limites du terrain examiné, 6 -- villes habitées par plus de 100000,7 - villes habitées par $50000-100000,8$ - villes habitées par 10 000-50000, 9 - villes habitées par moins de 10000 personnes et plus grands villages (s o u r c e: élaboration propre) 
szaru stwarzają dogodne warunki dla wypoczynku, krajoznawstwa i uprawiania wielu form turystyki kwalifikowanej.

Obok walorów przyrodniczych do największych atrakcji regionu należą elementy związane $\mathrm{z}$ odrębnością etniczną Kaszubów. Pomimo zawiłej historii i wielowiekowych nacisków germanizacyjnych, ludność tutejsza zdołała zachować swą tożsamość przez pielęgnowanie tradycji przekazywanych z pokolenia na pokolenie. Odrębność etniczna najsilniej zaznacza się w mowie. Język kaszubski do dnia dzisiejszego zachował nie spotykane gdzie indziej archaizmy, odrębny akcent, cechy fonetyczne i bogate słownictwo (P o p o w s k a - T a b o r s k a 1980). W kulturze materialnej, związanej głównie z życiem ludności na wsi, charakterystycznymi cechami odznaczało się budownictwo ludowe, rzemiosło i zazębiająca się z nim sztuka. W kulturze duchowej bogato ukształtowana została sfera wierzeń, zwyczajów i obrzędów oraz folklor muzyczny i literacki.

Wiele z elementów kultury kaszubskiej przetrwało do dnia dzisiejszego. W niektórych wsiach spotkać można drewnianą zabudowę, pochodząca jeszcze z ubiegłego stulecia. W krajobrazie widoczne są liczne przydrożne kapliczki i krzyże. Dynamiczny rozwój przeżywają niektóre dziedziny sztuki ludowej hafciarstwo, rzeźbiarstwo i malarstwo na szkle. Inne odradzają się po okresie zaniku, jak rogarstwo i plecionkarstwo z korzeni sosny. W warsztacie garncarskim w Chmielnie wytwarzana jest ceramika wg tradycyjnych technik i form. W wielu miejscowościach działają zespoły regionalne prezentujące dawny strój ludowy, instrumenty i folklor muzyczny. Zwyczaje i obrzędy utrwalane są podczas organizowanych co roku imprez kulturalnych i folklorystycznych. Na obszarze badań znajduje się sześć muzeów gromadzących zabytki kultury kaszubskiej, a wśród nich najstarszy w Polsce skansen - Kaszubski Park Etnograficzny we Wdzydzach Kiszewskich.

Na podstawie przeprowadzonej w terenie inwentaryzacji dóbr kultury kaszubskiej opracowano waloryzację miejscowości. Waloryzacji dokonano metodą bonitacji punktowej, polegającą na przyporządkowaniu wybranym elementom dziedzictwa kulturowego określonych wartości liczbowych. Jej efektem było określenie atrakcyjności turystycznej poszczególnych miejscowości i rozmieszczenia obszarów o najbogatszych walorach kulturowych. Ocenie poddano 28 miejscowości, których rangę i lokalizację prezentuje mapa (rys. 2).

$\mathrm{Na}$ obszarze badań wyodrębnić można dwa regiony szczególnie zasobne w pozostałości tradycyjnej kultury kaszubskiej. Pierwszy z nich położony jest na północ od linii Sulęczyno-Stężyca-Szymbark. Obejmuje on wsie o bardzo różnorodnych elementach dziedzictwa kulturowego. Oprócz miejscowości, w których zachowały się fragmenty dawnej zabudowy, znajdują się tu liczne ośrodki sztuki ludowej i folkloru oraz cztery spośród sześciu muzeów. Większość ośrodków położona jest na terenie Kaszubskiego Parku Krajobrazowego, co podnosi ich atrakcyjność turystyczną. Drugi z regionów pokrywa się niemal 


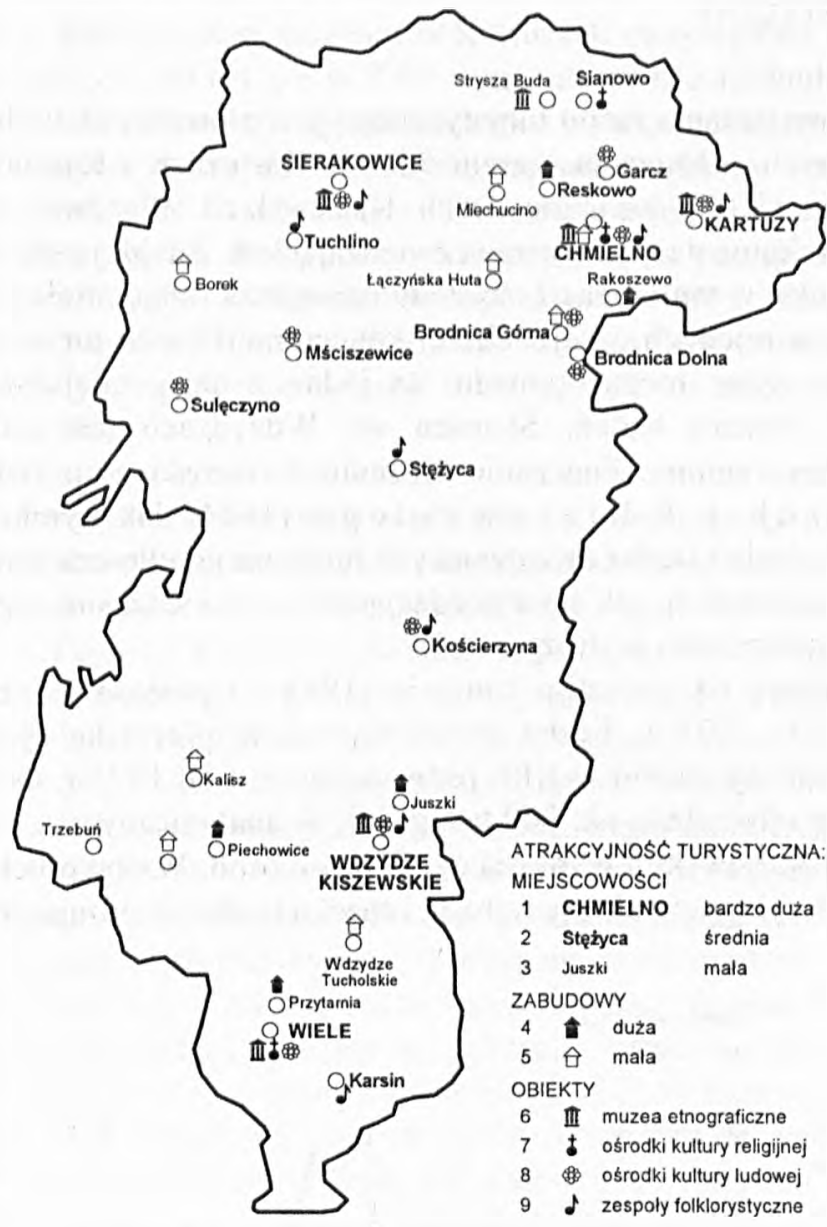

Rys. 2. Walory kulturowe obszaru badań (1994)

Atrakcyjność turystyczna miejscowości: 1 - bardzo duża, 2 - duża, 3-ze względu na zabudowę: a - duża, b - mala. Walory kulturowe: 4-muzea etnograficzne, 5-ośrodki kultu religijnego, 6-ośrodki sztuki ludowej, 7 -zespoły folklorystyczne (ź r ó d ł o: opracowanie własne)

Dessin 2. Les valeurs culturelles du terrain examiné (1994)

Attraits touristiques des localités: 1 -très grands, 2 - grands, 3 - aménagement: a - attrayant, $b$ - peu attrayant, 4 - musées ethnographiques, 5 - centres du culte religieux, 6 - centres de l'art populaire, 7 -ensembles folkloriques (s o u $\mathrm{r}$ c e: élaboration propre basée sur les données obtenues dans les musées)

z terenem Wdzydzkiego Parku Krajobrazowego. Można go nazwać „zagłębiem budownictwa ludowego", gdyż skupia wiele wsi o zachowanym pierwotnym układzie przestrzennym i drewnianej zabudowie. Jego centrum stanowią Wdzydze Kiszewskie, wieś która, uzyskała w waloryzacji największą liczbę punktów. 


\section{RUCH TURYSTYCZNY}

Szczegółowe badania ruchu turystycznego przeprowadzono w dwóch obiektach recepcyjnych - Muzeum Kaszubskim w Kartuzach i Kaszubskim Parku Etnograficznym (KPE) we Wdzydzach Kiszewskich. Placówki te posiadaja najpełniejszą dokumentację dotyczącą zwiedzających. Znajdują się one w miejscowościach, które w waloryzacji uzyskały najwyższą rangę atrakcyjności i zlokalizowane są w rejonach o największej koncentracji ruchu turystycznego. Powyższe muzea uznać można ponadto za jedne $\mathrm{z}$ najważniejszych obiektów turystycznych obszaru badań. Skansen we Wdzydzach jest jedynym tego rodzaju obiektem regionu. Znaczenie Muzeum Kaszubskiego potwierdza praca S. K a c z m a r e k i S. L i s z e w s k i e g o (1989). Jak wynika z przedstawionych w niej badań liczba zwiedzających muzeum przekracza zarówno liczbę nocujących w Kartuzach, jak i przyjeżdżających z wycieczkami organizowanymi przez miejscowe biura podróży.

Dokumentację od początku istnienia (1948 r.) posiada jedynie muzeum w Kartuzach. Do 1973 r. liczba zwiedzających tę placówkę systematycznie wzrastała. Rejestracja ruchu w KPE prowadzona jest od 1975 r. Od tej daty do 1994 r. skansen odwiedziło ok. 800 tys. gości. W analogicznym czasie frekwencja w Muzeum Kaszubskim wyniosła ok. 750 tys. osób. W obu obiektach występowały charakterystyczne okresy wzrostu i spadku liczby zwiedzających (rys. 3).

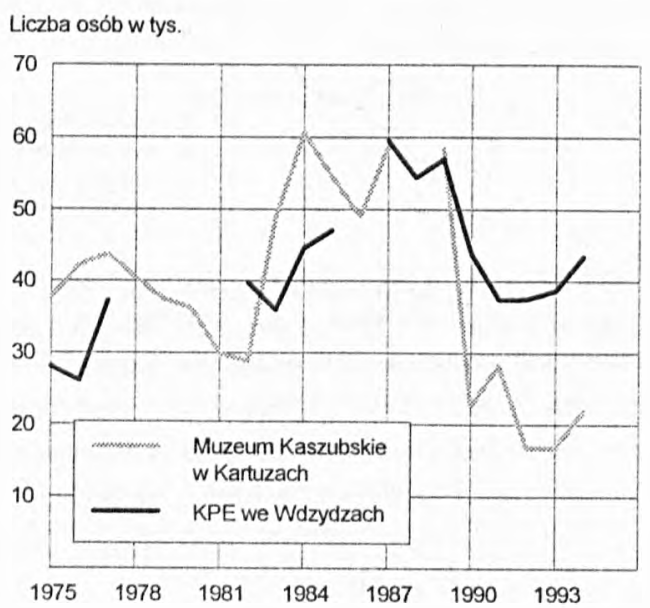

Rys. 3. Wielkość ruchu turystycznego w muzeach w latach 1975-1994

1 - Muzeum Kaszubskie w Kartuzach, 2 - Karuski Park Etnograficzny we Wdzydzach

(ź r ó d l o: opracowanie wlasne na podstawie sprawozdań z dzialalności muzeów)

Dessin 3. La grandeur du mouvement touristique dans les musées dans les années 1975-1994

1 - Musée Kachoube à Kartuzy, 2 - Parc Ethnographique Kachoube à Wdzydze

(s o u r c e: élaboration propre basée sur le compte-rendus de l'activité des musées) 
Do 1980 r. frekwencja w muzeum w Kartuzach utrzymywała się na wyrównanym poziomie (ok. 40 tys.), a w KPE wzrastała wraz z rozbudową skansenu. Wyraźny jej spadek zaznaczył się na początku lat osiemdziesiątych, w okresie napięć politycznych w kraju. Od 1983 r. nastąpił ponowny wzrost wielkości ruchu turystycznego. W latach 1983-1989 notowano jedne z najwyższych jego wartości. Kolejny spadek frekwencji widoczny jest na początku lat dziewięćdziesiątych. Liczba gości w Muzeum Kaszubskim w 1990 r. zmalała w stosunku do 1989 r. o ponad $60 \%$, zaś w KPE o ok. $35 \%$. Zarówno muzea, jak i społeczeństwo odczuły pogorszenie sytuacji materialnej związanej ze zmianami ustrojowymi w Polsce.

Występowanie szczytów frekwencji w sezonie letnim uznawane jest za jedno z najważniejszych kryteriów atrakcyjności turystycznej muzeów. Badaniami sezonowości objęto lata 1992-1994. Rozkład ruchu turystycznego w ciągu roku wykazuje podobieństwo do okresów wyznaczonych w pracy A. G e r l a c h - J ó s e f o w i c z (1975), charakterystycznych dla większości obiektów turystycznych w Polsce (rys. 4). Sezon turystyczny obejmuje okres wiosennych wycieczek szkolnych (maj, czerwiec) i letnich wakacji (lipiec, sierpień). Na te cztery miesiące przypadało w poszczególnych latach 73-82\% ruchu w Muzeum Kaszubskim i $85-88 \%$ we wdzydzkim skansenie. Maksimum frekwencji występuje zawsze w czerwcu, o czym decyduje duża liczba wycieczek szkolnych organizowanych w tym miesiącu. Miesiące powakacyjne są okresem przejściowym, a na pozostałe (listopad-kwiecień) przypada sezon martwy.

$\mathrm{Z}$ sezonem koreluje struktura ruchu turystycznego. Wiosną i jesienią przeważają turyści zwiedzający muzea $\mathrm{w}$ grupach, latem turyści indywidualni. Ogromny udział wśród grup mają wycieczki szkolne. W okresie styczeń-lipiec 1994 r. szkoły były organizatorami ok. 55\% wycieczek do Muzeum Kaszubskiego i $65 \%$ do skansenu we Wdzydzach. Latem rolę organizatorów przejmują od szkół ośrodki kolonijne i wczasowe zlokalizowane na Pomorzu Gdańskim.

Jak wynika z badań ankietowych, forma pobytu w danej miejscowości uzależniona jest od jej walorów i charakteru. Kartuzy jako miasto o walorach krajoznawczych, będące węzłem komunikacyjnym, ale jednocześnie ubogie $\mathrm{w}$ bazę noclegową odwiedzane są głównie w ramach wycieczek lub podczas przejazdu przez miejscowość. Wdzydze Kiszewskie położone w strefie atrakcyjnej krajobrazowo i dysponujące szeroką gamą różnorodnej bazy noclegowej są natomiast typową wsią letniskową. Przeważająca liczba ankietowanych w skansenie przebywała na urlopie w okolicznych ośrodkach wypoczynkowych, na kwaterach prywatnych lub kempingach. Głównym środkiem transportu w obu przypadkach był prywatny samochód. Z masowych środków komunikacji skorzystało jedynie 7\% zwiedzających muzeum w Kartuzach i ok. 4\% gości skansenu we Wdzydzach. Specyficznym środkiem transportu do Wdzydz, wsi położonej na szlaku wodnym Wdy, był kajak. 

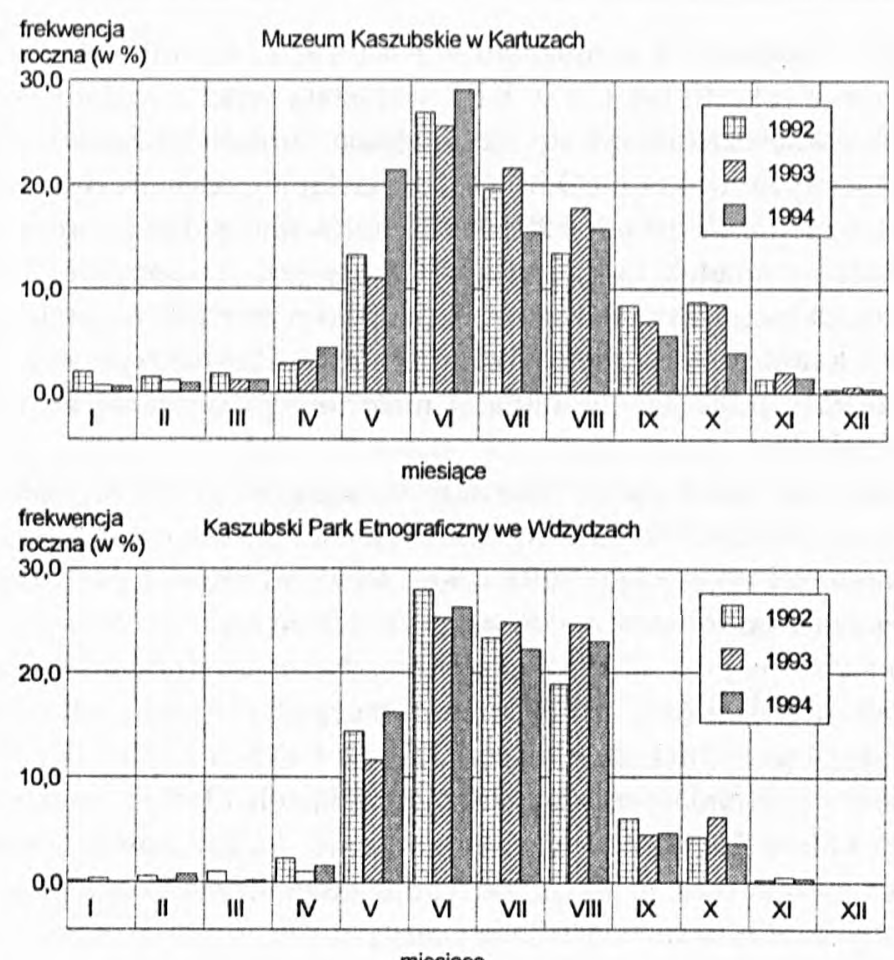

Rys. 4. Sezonowość ruchu turystycznego w muzeach w latach 1992-1994

(ź r ó d ł o: opracowanie własne na podstawie sprawozdań z dzialalności muzeów)

Dessin 4. Le caractère saisonnier du mouvement touristique dans les musées dans les années 1992-1994 (s o u r c c: élaboration propre basée sur le compte-rendus de l'activité des musées)

Cechy społeczno-demograficzne indywidualnie zwiedzających muzea były w ogólnym zarysie w obu przypadkach zbliżone. Znaczną część gości muzealnych stanowily rodziny $\mathrm{z}$ dziećmi, przebywające na urlopie. Zadecydowało to w dużej mierze o strukturze wiekowej ankietowanych. Najliczniejsza grupe stanowiły osoby w wieku 31-40 lat (około 1/3 w obu obiektach). Nieco mniejszy udział (po ok. 1/5) miały osoby z przedziałów wiekowych 21-30 i 45-55. Łącznie turyści $z$ trzech wyżej wymienionych grup stanowili ponad $75 \%$ respondentów. W obu muzeach dominowały osoby legitymujące się co najmniej wykształceniem średnim (w Muzeum Kaszubskim - 80\%, w KPE - ponad 83\%), a wśród nich znaczna liczba posiadała wykształcenie wyższe. Bardzo niewiele osób ukończyło jedynie szkolę zawodowa. Na pozostałą grupę składali się uczniowie szkół, studenci oraz osoby starsze z wykształceniem podstawowym. Struktura zawodowa zwiedzających była bardzo zróżnicowana, przy czym w dużej mierze związana z poziomem wykształcenia. Najliczniejszą grupę tworzyły osoby związane zawodowo z nauką i oświatą - pracownicy szkół, uczelni 
i placówek oświatowo-kulturalnych. Równorzędne co do liczebności grupy tworzyli uczący się, emeryci i przedstawiciele kadr inżynieryjno-technicznych. Ci ostatni pochodzili w większości z dużych ośrodków miejskich.

Pochodzenie terytorialne turystów indywidualnych określono na podstawie badań ankietowych, zaś turystów zbiorowych na podstawie rachunków ze sprzedaży biletów w okresie od stycznia do lipca 1994 r. Spośród ankietowanych w Muzeum Kaszubskim 73\% pochodziło z Polski. Przybyli oni z 41 miejscowości położonych w 17 województwach. W KPE goście krajowi stanowili $82 \%$ zwiedzających. Byli oni mieszkańcami 44 miejscowości znajdujących się również w 17 województwach. Zdecydowana większość pochodziła $\mathrm{z}$ dużych i średnich miast. Tylko niecałe $11 \%$ to mieszkańcy wsi.

W obu obiektach najliczniej reprezentowane było woj. gdańskie, a szczególnie rejon Trójmiasta (ok. 1/3 zwiedzających). Na drugim miejscu pod względem liczebności znalazly się osoby pochodzace z największej w Polsce aglomeracji miejsko-przemysłowej - Górnego Śląska. Do Wdzydz przybyło ponadto wielu mieszkańców województw ościennych - bydgoskiego i słupskiego. Wśród pozostałych respondentów przeważały osoby zamieszkałe $w$ dużych miastach Polski - Warszawie, Lodzi, Poznaniu. Nieliczni turyści reprezentowali ośrodki miejskie całego kraju, pomijając obszary wschodniej jego części, skąd przybyła bardzo znikoma liczba osób. Wymowna okazała się analiza odległości miejsc stałego zamieszkania zwiedzających od miejscowości, w których znajdują się muzea (rys. 5).

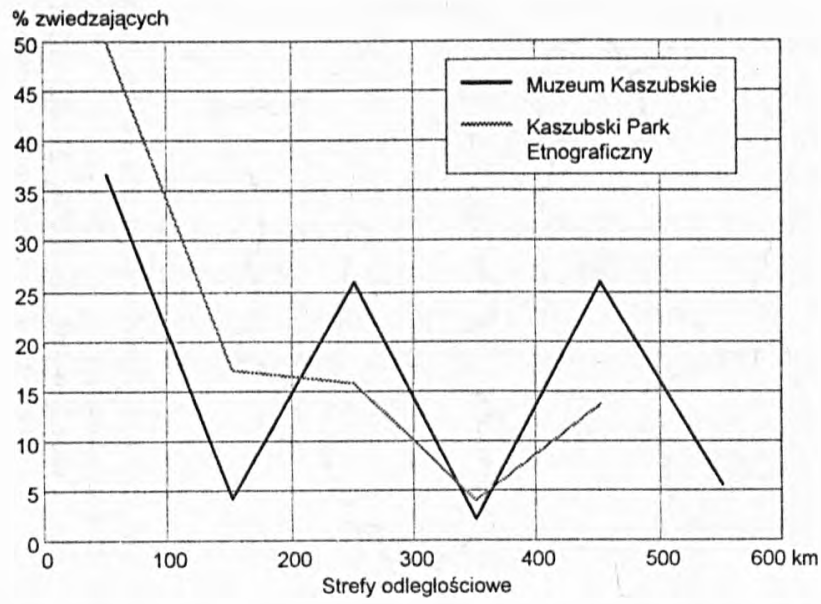

Rys. 5. Liczba osób przybyłych do muzeów w zależności od odległości od miejsca zamieszkania 1 - Muzeum Kaszubskie w Kartuzach, 2 - Kaszubski Park Etnograficzny we Wdzydzach

( $z$ r ó d ł o: opracowanie własne na podstawie ankiet z lipca 1994 r.)

Dessin 5. Le nombre des visiteurs des musées selon l'éloignement de leur lieu ordinaire d'habitation 1 - Musée Kachoube à Kartuzy, 2 - Parc Ethnographique Kachoube à Wdzydze (s o u r c e: élaboration propre basée sur les enquêtes faites en juillet 1994) 

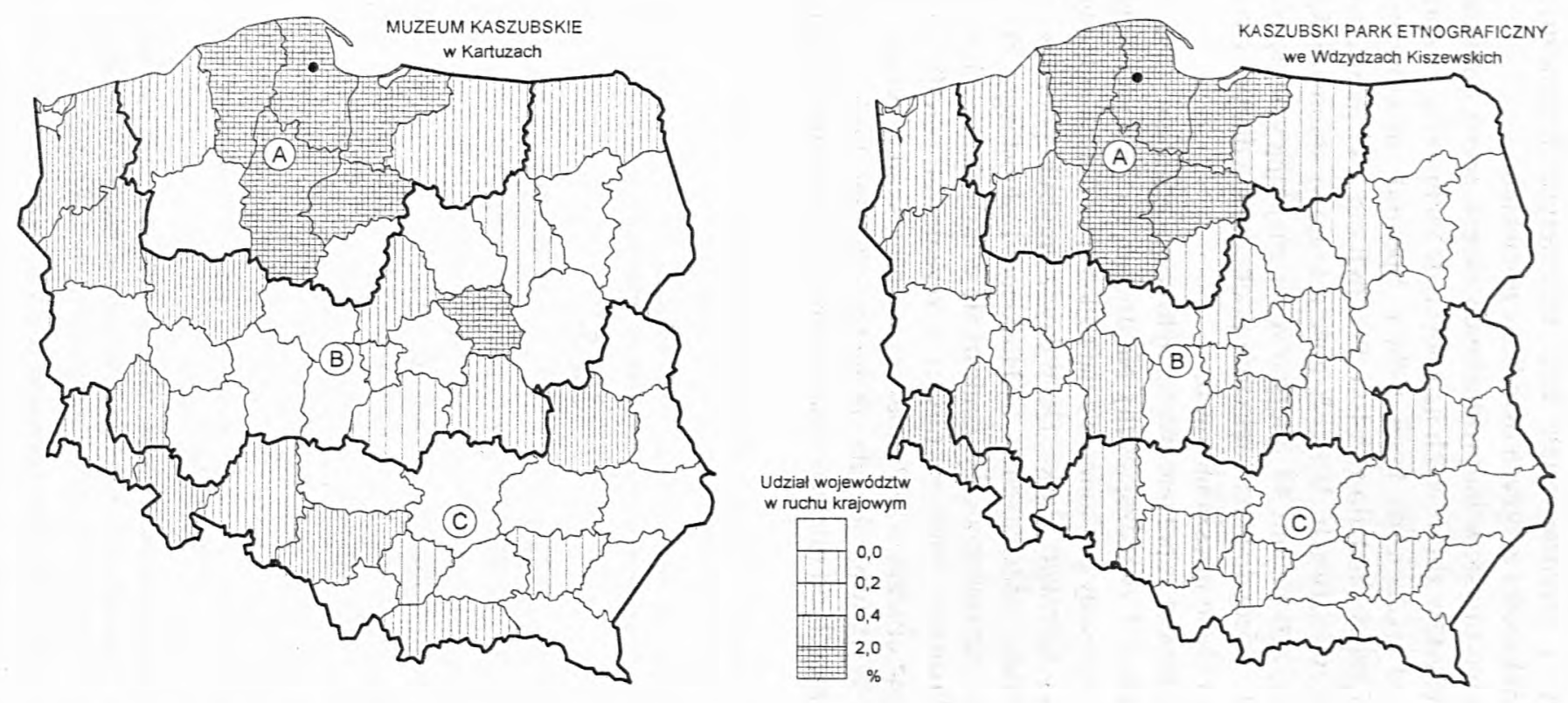

Rys. 6. Pochodzenie terytorialne uczestników krajowego ruchu wycieczkowego do muzeów w okresie styczeń-lipiec 1994.

Strefy odległości do miejscowości: A - do $200 \mathrm{~km}, \mathrm{~B}-200-400 \mathrm{~km}, \mathrm{C}-$ powyżej $400 \mathrm{~km}$. Udział województw w krajowym ruchu wycieczkowym: $1-0,0 \% ; 2-0,0-0,2 \% ; 3-0,2-0,4 \% ; 4-0,4-2,0 \%, 5-$ powyżej $2 \%$ (ź r ó d l o: opracowanie własne na podstawie rachunków ze sprzedaży biletów)

Dessin 6. L'origine territoriale des excursionnistes qui ont visité le musée dans les mois janvier-juillet 1994.

Eloignement du lieu ordinaire d'habitation égale: A -jusqu'à $200 \mathrm{~km}, \mathrm{~B}-200-400 \mathrm{~km}, \mathrm{C}-$ plus de $400 \mathrm{~km}$. La participation des voïvodies dans le mouvement d'excursions: $1-0,0 \% ; 2-0,0-0,2 \% ; 3-0,2-0,4 \% ; 4-0,4-2,0 \% ; 5-$ plus de $2 \%$ (s o u r c e: élaboration propre basée sur le nombre des tickets vendus) 
Ponad 1/3 turystów w Kartuzach i 1/2 we Wdzydzach pochodziła z obszaru bezpośrednio sąsiadującego $\mathrm{z}$ tymi ośrodkami, położonego w promieniu $100 \mathrm{~km}$. W jego obrębie znalazło się całe woj. gdańskie, częściowo bydgoskie i słupskie. W przypadku Wdzydz zależność między odległością miejsca zamieszkania od wsi i liczbą turystów jest prosta. Liczba osób z poszczególnych stref maleje wraz ze wzrostem odległości. Wśród zwiedzających muzeum w Kartuzach znalazło się natomiast wiele osób przybyłych z odległości $200-300 \mathrm{~km}$. Strefa ta obejmuje wspomniane już miasta Polski Środkowej. W obu przypadkach obszarem, z którego pochodziła znaczna część gości była strefa 400-500 km, w obrębie której położona jest aglomeracja górnośląska. Powyższe dane nasuwają wniosek o dużym skupieniu miejsc zamieszkania turystów. Koncentrują się one głównie w województwach pomorskich oraz na obszarach o dużym stopniu urbanizacji i znacznym potencjale ludnościowym (rys. 6).

Goście zagraniczni stanowili $27 \%$ zwiedzających indywidualnie muzeum w Kartuzach i $18 \%$ we Wdzydzach. Z ogólnej liczby ankietowanych obcokrajowców aż $61 \%$ pochodziło z Niemiec. Dla wielu z nich miejscem docelowym były Mazury bądź Gdańsk. Turyści niemieccy spędzający na Kaszubach dłuższy okres czasu byli zwykle związani z tym regionem korzeniami, posiadali tu rodzinę lub bliskich znajomych. Wśród pozostałej grupy cudzoziemców znaleźli się turyści z krajów Beneluksu, Skandynawii, Wysp Brytyjskich i USA.

Analiza pochodzenia grup zorganizowanych została oparta na rachunkach ze sprzedaży biletów. Należy jednak zaznaczyć, iż w wielu przypadkach rachunki ukazują miejsce organizacji, a nie pochodzenia wycieczek, co może wpływać na zniekształcenie obrazu miejsca zamieszkania uczestników grup. Podobnie jak w przypadku turystów indywidualnych, większość grup przybyła z miejscowości bliskich, położonych w odległości do $100 \mathrm{~km}$. Ma to związek z dużą liczbą wycieczek organizowanych przez pomorskie szkoły, w których zwiedzanie muzeów regionalnych zawarte jest w programie nauki oraz wycieczek kolonijnych i z ośrodków wczasowych. Z obszaru odległego o $200-400 \mathrm{~km}$ pochodziło jedynie 10\% zwiedzających grupowo Muzeum Kaszubskie i $6 \%$ skansen, a ze strefy najbardziej odległej (ponad $400 \mathrm{~km}$ ) bardzo niewiele grup (rys. 6). Wśród wycieczek zagranicznych dominowały grupy z Niemiec. Pojedyncze wycieczki pochodziły z różnych krajów Europy Zachodniej.

\section{ATRAKCYINOŚĆ TURYSTYCZNA KULTURY KASZUBSKIEJ}

W ŚWIETLE BADAŃ RUCHU TURYSTYCZNEGO

$\mathrm{Z}$ punktu widzenia wykorzystania dziedzictwa kulturowego w turystyce istotnym było poznanie częstotliwości przyjazdów do muzeów, ich motywów oraz opinii na temat zgromadzonych w muzeach zabytków, a także walorów regionu. Przeważająca liczba turystów zwiedzała muzeum po raz pierwszy. Dla 17\% goś- 
ci Muzeum Kaszubskiego i $21 \%$ skansenu była to druga wizyta. Szczególnie dużą liczbę osób, które zwiedzaly obiekt po raz kolejny, zanotowano we Wdzydzach.

Najczęściej udzielaną odpowiedzią na pytanie o motywy było zainteresowanie kulturą lub etnografią oraz chęć obejrzenia regionalnego muzeum. Lącznie te dwie odpowiedzi stanowiły ok. $75 \%$ udzielonych w obu obiektach. Dla osób, które zwiedzały muzeum po raz kolejny podstawowym motywem ponownej wizyty był sentyment do znajomych miejsc. Dla niektórych obiekty te były na tyle atrakcyjne, by przyprowadzić krewnych i znajomych. Wielu turystów w skansenie oznajmiło, że przyjeżdża tu rokrocznie aby obserwować jego rozbudowę. Stosunkowo nieduża grupa trafiła do muzeum przypadkowo. Głównym źródłem informacji o regionie była dla większości relacja znajomych. Na drugim miejscu wymieniano przewodniki turystyczne. Sądzić można, że dla wielu turystów wizyta w powyższych obiektach była wyborem świadomym i została wcześniej zaplanowana (rys. 7).

Prawie 94\% ankietowanych wydało pozytywne opinie na temat eksponowanych zbiorów. Bardzo niewiele osób wyraziło stosunek obojętny, stwierdzając, że muzeum nie różni się niczym szczególnym od innych. O zadowoleniu gości
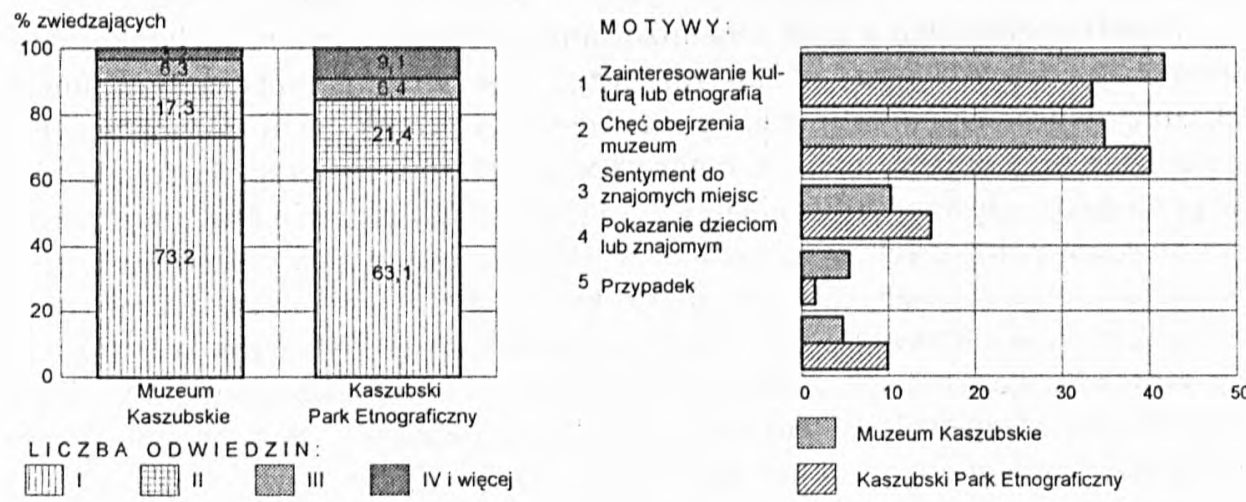

Rys. 7. Częstotliwość i motywy przybycia do muzeów A - częstotliwość przyjazdów, B - motywy przyjazdów; I - Muzeum Kaszubskie w Kartuzach, II - Kaszubski Park Etnograficzny we Wdzydzach, I - zainteresowanie kulturą lub etnografią 2 - chęć obejrzenia regionalnego muzeum, 3 - sentyment do znajomych miejsc, 4 - pokazanie dzieciom, znajomym, 5-przypadek, (ź r ó d lo: opracowanie własne na podstawie ankiet z lipca $1994 \mathrm{r}$.)

Dessin 7. La fréquence et les motifs des arrivées dans les musées A - fréquence des arrivées, B - motifs des arrivées, I - Musée Kachoube à Kartuzy, II - Parc Ethnographique Kachoube à Wdzydze, 1 - intérêt porte à la culture et à l'ethnographie, 2 - désir de voir le musée régional, 3 - stable sentiment pour les lieux connus, 4 - désir de montrer les objets aux siens, 5 - par hasard, (s o u r c e: élaboration propre basée sur les enquêtes faites en juillet 1994) 
świadczy również fakt, iż tylko 18 osób nie wyraziło chęci ponownych odwiedzin. Zdecydowaną chęć powrotu zadeklarowała 1/3 zwiedzających Muzeum Kaszubskie i połowa we wdzydzkim skansenie. Pozostali przyjęli taką możliwość przy okazji pobytu w okolicy.

$21 \%$ respondentów przypisało elementom dziedzictwa kulturowego decydującą rolę w atrakcyjności turystycznej ziemi kaszubskiej. Dla $40 \%$ podstawowym czynnikiem przyciągającym były jednak walory przyrodnicze. Równie liczna grupa osób stwierdziła, że oba rodzaje walorów stanowią o obrazie i specyfice regionu. Taka struktura wypowiedzi sugeruje, że walory kulturowe Kaszub są dostrzegane i chociaż nie decydują o wyborze miejsca wypoczynku, to wspólnie z elementami środowiska naturalnego składają się na jego atrakcyjność turystyczna. Z $Z$ wypowiedzi turystów wynika, że szczególnie dużą popularnością cieszą się wyroby rękodzielnicze i sztuki ludowej oraz letnie imprezy folklorystyczne. Te ostatnie poprzez swój rozrywkowy charakter są dobra okazją do prezentacji cząstki kaszubskiego folkloru. Jedną z imprez o największym zasięgu jest Jarmark Wdzydzki odbywający się od ponad 20 lat na terenie skansenu. Jarmark przyciąga co roku tysiące gości. W 1994 r. przybyło na niego ponad 6 tys. osób. $Z$ przeprowadzonych wywiadów wynika, że ma on swoich stałych wielbicieli, którzy przyjeżdżają do $\mathrm{Wdzydz}$ rokrocznie, nawet $\mathrm{z}$ odległych części kraju.

Podsumowując stwierdzić można, że chociaż poznanie dziedzictwa kulturowego Kaszubów rzadko bywa głównym celem podróży, jego elementy wkomponowane w krajobraz stanowią atrakcję turystyczną. Odpowiednie ich wyeksponowanie i promocja mogłaby, zdaniem autorki, przyczynić się do rozwoju na Kaszubach turystyki etnograficznej.

\section{PIŚMIENNICTWO}

G e r l a c h -J ó s e fo w i c z A., 1975, Wybrane problemy przepustowości turystycznej muzeów, „Zeszyty Naukowe Instytutu Turystyki”, Warszawa, s.126-140.

G u l g o w s k i I., 1924, Kaszubi, Biblioteka Geograficzna, Orbis, Kraków.

K a c z m a r e k S., L i s z e w s k i S., 1989, Funkcja turystyczna Kartuz, „Acta Universitatis Lodziensis", Turyzm, nr 5, s. 67-91.

K o n d r a c k i J., 1988, Geografia fizyczna Polski, PWN, Warszawa.

P o p ow sk a - T a bors k a H., 1980, Kaszubszczyzna. Zarys dziejów, PWN, Warszawa. 


\section{RÉSUMÉ}

L'article a pour but l'évaluation de l'exploitation de l'héritage culturel des Kachoubes par le mouvement touristique. Sous la notion de l'héritage culturel, l'auteur comprend tous les symptômes de la culture matérielle et toutes les créations de celle spirituelle. Le terrain de recherches embrassait 9 communes de la voïvodie de Gdańsk, identifiées avec la sous-région ethnographique de la Kachoubie Centrale et Méridionale.

Le travail est basé sur les recherches d'inventaire et celles du mouvement touristique, faites au Musée Kachoube à Kartuzy at dans le Parc Ethnographique à Wdzydze Kiszewskie.

Les valeurs naturelles, l'accessibilité facile et l'aménagement de la région créent des conditions favorables de repos, de tourisme chorographique et qualifié. Outre cela ce terrain est une vive région ethnographique, où sont maintenus la language propre et plusieurs éléments de la culture populaire. En s'appuyant sur l'inventaire des biens culturels, on a valorisé les localités et distingué deux régions particulièrement attrayantes du point de vue de la chorographie.

Les examens faits dans les musées on démontré, que la grandeur changeante du mouvement touristique était liée avec la situation politique et économique en Pologne. Dans la période 19751994, il y avait le plus de touristes dans la deuxième moitié des années quatre-vingts, le moins au début des années quatre-vingts et quatre-vingt-dix. La disposition du mouvement touristique changeait suivant les saisons de l'année. La saison touristique dure dès le mois de mai jusqua'au mois d'août, et l'affluence des touristes est alors la plus grande ( $80 \%$ de la fréquence annuelle). Au printemps les plus nombreuses sont les excursions scolaires, en été dominent les touristes individuals. Dans la période examinée, parmi les visiteurs des musées il y avait beaucoup de familles avec les enfants, mais dominaient la jeunesse et les personnes à l'âge productif (21-25 ans), ayant reçu l'enseignement secondaire ou supérieur. Dans leur grande majorité, les visiteurs venaient des villes grandes ou moyennes. Parmi eux les plus nombreux étaient les habitants des voïvodies de la Poméranie, de grandes villes de la Pologne Centrale et des régions puissamment peuplées. Les étrangers constituaient $27 \%$ des visiteurs du musée à Kartuzy et $18 \%$ - de celui de Wdzydze. Dominaient les Allemands (61\%).

L'intérêt porté à la culture de la région, le désir de revoir le lieu sympathique et déjà connu et de le montrer aux siens - c'étaient des motifs principaux des visites dans les musées.

Les opinions des personnes enquêtées sur les collections exposées étaient très favorables. Plusieurs visiteurs pensaient y revenir à l'occasion.

Dans leur majorité les touristes trouvent que les valeurs culturelles de la Kachoubie sont très attrayantes. A la base des recherches qu'on a faites, on peut constater, que bien que la connaissance de l'héritage constitute rarement le but du voyage, la culture populaire avec les éléments du milieu naturel décide de la spécificité et de la séduction de la région donnée.

Traduit par Lucjan Kowalski

\section{SUMMARY}

The aim of the article was to evaluate the use of the cultural heritage of Kashuby through the tourist traffic. By the cultural heritage the author understands all signs of traditional folklore culture, consisting of the material culture elements, as well as the products of spiritual culture. The research area comprised 9 communes of the Gdańsk voievodship, which are treated as the ethnographic subregion of Central and South Kashuby. 
The article is based on the cataloguing research and on the study of the tourist traffic carried out in the Kashuby Museum in Kartuzy and in the Kashuby Ethnographic Park in Wdzydze Kiszewskie.

Natural advantages, good accessibility and management of the area create favourable conditions for recreation, sightseeing and classified tourism. The area is a living ethnographic region, which retained its own language and numerous elements of folklore culture. On the basis of the listing of the cultural assets, all places were evaluated and two particularly attractive regions were selected,

The research carried out in the museums showed that changes in the tourist traffic were mainly connected with the political and economic situation in Poland. Between 1975 and 1994 the most intensive traffic was observed in the second half of the1980s, and the least intensive at the beginning of 1980s and 1990s. The distribution of the tourist traffic had a strongly seasonal character. The tourist season covers the period from May to August $(80 \%)$. In spring school excursions constitute a vast part of the traffic, while in summer individual tourists are the majority.

A big part of the museum visitors were families with children. Among them people at the working age were predominant ( $21-55$ years of age). They had graduated either from the secondary school or from university. Another large group were children at school age. The majority came from large and medium-sized cities. When the places of origin were examined, it turned out that they were territorially condensed. Most visitors came from the seaside voievodships, large cities of Central Poland and the regions of considerable population potential. Foreign visitors to the museums constituted $27 \%$ in Kartuzy and $18 \%$ in Wdzydze. Among the foreign tourists the majority came from Germany (61\%).

The main reason for the visit was interest in the culture of the region, and the people who had visited the objects before felt sentimental about them and wanted to show them to family and friends. $94 \%$ of the people in the research were expressing positive opinions about the exhibits, and a large majority said they were planning to come again.

The cultural assets of Kashuby are seen by most as attractive. On the basis of the research one can state that although getting to know the cultural heritage rarely becomes the main reason for the trip, the folklore culture, along with the elements of natural environment shapes the special and attractive character of the region. 